\title{
Spontaneous Rupture of a Hepatic Hydatid Cyst with Anaphylaxis: A Case Report
}

\author{
Ömer Arda Çetinkaya, Süleyman Utku Çelik, Akın Fırat Kocaay, Elvan Onur Kırımker, Cihangir Akyol \\ Department of General Surgery, Ankara University School of Medicine, Ankara, Turkey
}

\section{ABSTRACT}

Introduction: Hydatid cyst rupture is a rare but life-threatening complication of a hepatic hydatid cyst, and it can result in anaphylactic reactions.

Case Report: Here we report a spontaneous rupture of a hepatic hydatid cyst presenting with abdominal pain and anaphylaxis and its successful management in a 25-year-old Turkish woman.

Conclusion: The combination of abdominal pain and anaphylaxis is a rare clinical feature in daily surgical practice. Hydatid cyst rupture must be kept in mind for patients with abdominal pain and anaphylactic findings for early detection and intervention.

Keywords: Anaphylaxis, hepatic, hydatid cyst, rupture

Received: 25.08.2015 Accepted: 20.10.2015 Available Online Date: 04.02.2016

\section{Introduction}

Hydatid cysts commonly occur in the liver (75\%) and lungs (25\%) by the infection of a zoonotic parasite known as Echinococcus. The incidence of hydatid cysts varies in different regions all over the world. Endemic regions are east Mediterranean (Turkey, Greece, Cyprus, etc.), Middle East (Iran, Iraq, etc.), Russia, China, Australia, and Spain with an annual incidence of 1-200/100000 individuals (1-3). The mostly definitive host for the adult cestode is dog. The host releases eggs from the stool and infects the intermediate host (commonly sheep), and embryos are released and passed into the portal and lymphatic system. Humans are aberrant intermediate hosts and get infected from food (eggs from vegetables, water, etc.) or from the hair of canines by the fecal-oral route. The parent cyst has two membranous layers of inner (germinative) and outer (hyaline) membranes. Protoscolices originate from the germinative membrane, and infectious daughter cysts frequently originate from the parent cyst $(1,3)$.

The most common disease is seen in the right lobe of the liver. Most patients have one cyst (70\%), but some have multiple cysts (20\%-40\%). The diameter of cysts varies from few centimeters to as large as $20-30 \mathrm{~cm}$. Rupture rate is commonly reported as approximately $20 \%$ and is associated with young age, superficial localization, trauma, and large cyst size. Complications vary from abdominal pain to death according to anaphylaxis, including biliary relation, cholangitis, portal hypertension, ascites, and abscess. The anaphylaxis rate has been reported as 10\% in all ruptured cases in one series $(4,5)$.

The present case describes a 25-year-old Turkish woman presenting with abdominal pain and evidence of anaphylaxis, which is uncommon in our daily surgical practice.

\section{Case Report}

A 25-year-old woman was admitted to our emergency department with a 24-h history of abdominal pain, abdominal distention, and nausea and vomiting. There was no history of trauma, medicine intake, surgery, systemic disease, or similar previous complaints. On admission, the patient was tachypneic (25/min), tachycardic (115/min) with sinus rhythm, hypotensive ( $80 / 50$ $\mathrm{mmHg}$ ), and hyperthermic at $38.1^{\circ} \mathrm{C}$. Generalized rebound tenderness was observed during the abdominal examination. Also, 
deep swelling around the eyes and lips and urticarial lesions were seen over the thigh and trunk. Initial laboratory investigations revealed leukocytosis $\left(11500 / \mathrm{mm}^{3}\right)$, hemoglobin level of $12.1(11.7-$ 16.1) $\mathrm{g} / \mathrm{dL}$, C-reactive protein level of $103(0-3) \mathrm{mg} / \mathrm{L}$, creatinine level of 2.1 (0.7-1.2) mg/dL, sodium level of 141 (136-145) mEq/L, and potassium level of 3.1 (3.5-5.1) $\mathrm{mEq} / \mathrm{L}$, and her liver function tests were normal. Her electrocardiogram, chest X-ray, and plain abdominal Xray were also normal. Aggressive intravenous fluid resuscitation with an isotonic crystalloid fluid solution $(20 \mathrm{~mL} / \mathrm{kg}$, intravenously, in first $30 \mathrm{~min}$ ) was immediately initiated, and adrenaline $(0.01 \mathrm{mg} / \mathrm{kg}$, intramuscularly), pheniramine maleate (45.5 mg, intravenously), and hydrocortisone (80 mg, intravenously) were administered to preoperatively prevent anaphylactic reactions.

An abdominal computed tomography scan demonstrated a lesion with a diameter of $120 \mathrm{~mm}$ that completely filled the right lobe of the liver, which was likely to be a ruptured hydatid, and significant free fluid in the perihepatic and perisplenic areas and pelvis (Figure 1). After informed consent was obtained, laparotomy and aggressive irrigation were planned, and a cavity of the hydatid cyst located in the right lobe of the liver with a diameter of $20 \mathrm{~cm}$ was seen (Figure 2). Approximately $1250 \mathrm{~mL}$ of infectious free fluid containing multiple daughter cysts disseminated throughout the abdomen. The fluid was suctioned after taking culture samples, the germinative membrane lining the cystic cavity and daughter cysts were removed, and the anterior wall of the cyst was deroofed (Figure 3). No biliary leakage and other pathological evidence were seen on exploration. The cyst pouch and whole abdominal cavity were irrigated with diluted poviodine (10\%) and the isotonic crystalloid fluid solution. Omentoplasty was performed, and the surgical procedure was completed after drains were placed into the cyst pouch, right subhepatic space, and recto-vesical areas.

Postoperatively, the patient was managed in the Surgical Intensive Care Unit and was initiated on albendazole, ceftriaxone, and metronidazole. The last drain was removed on the 10th post-operative day without any complication, and the patient was discharged with albendazole therapy for at least 3 months.

\section{Discussion}

Hydatid cysts of the liver are commonly asymptomatic (3). They may be detected incidentally by imaging modalities (ultrasonography, computed tomography, etc.) for an unrelated indication $(3,4)$. Computed tomography is the most sensitive imaging modality for showing cyst rupture. Ultrasonography is also helpful. Jaundice is a frequent but non-specific symptom to diagnose hydatid disease (5). Generally, the size and location of cysts define the presence of the disease. Serious and mortal complications such as intraperitoneal rupture (1.6\%-16\%), anaphylaxis (1\%-12.5\%), or biliary tract events may facilitate the diagnosis, as in our case $(1,3,5)$. The mortality rate can reach $23 \%$ (5). Ruptured hydatid cysts are classified into three groups: contained, communicating, and direct. In contained rupture cysts, contents are found locally surrounding the pericyst. In communicating rupture cysts, contents are related to

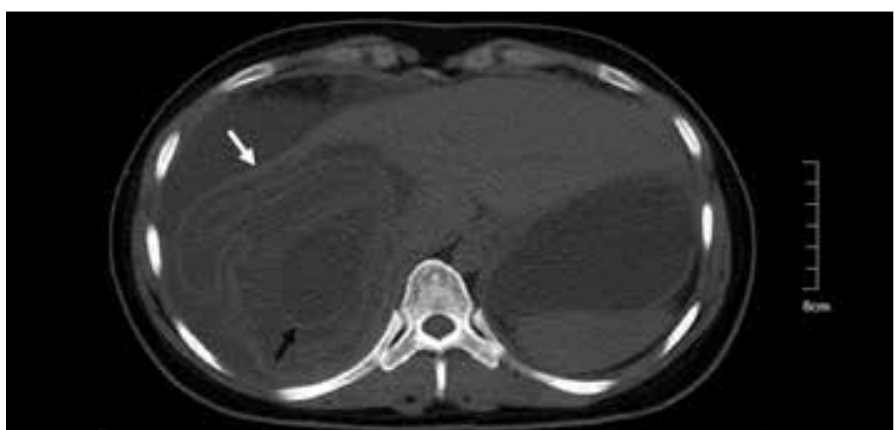

FIG. 1. Computed tomography scan demonstrating a partially collapsed large cystic lesion (white arrow) and detached laminated membrane (black arrow) with widespread free fluid.

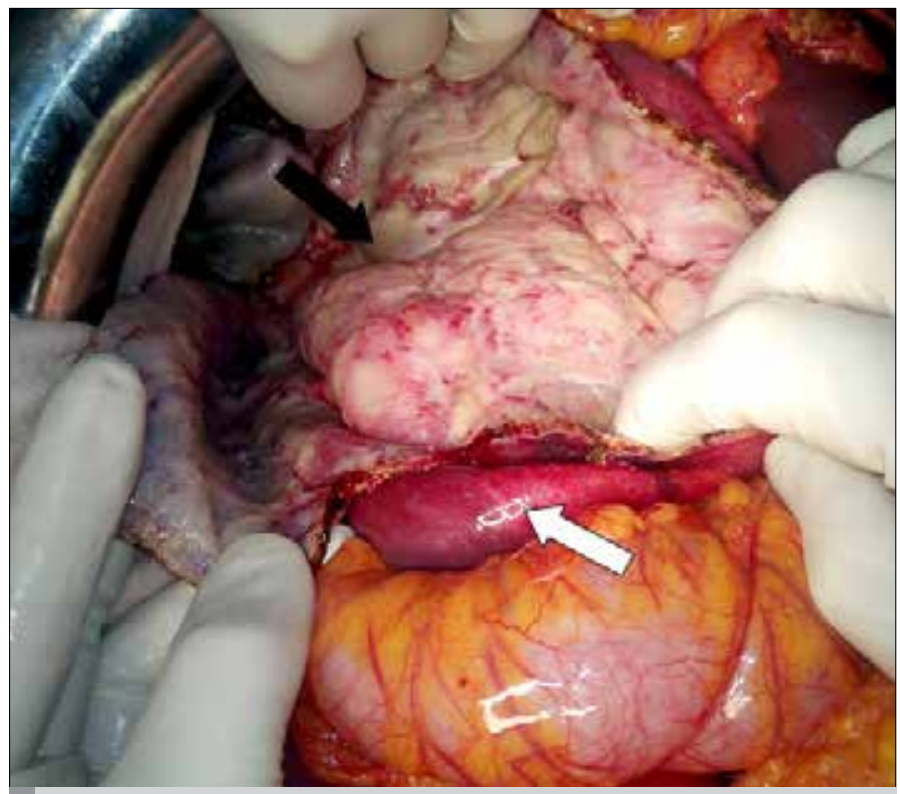

FIG. 2. Intra-operative view of the ruptured hydatid cyst; cystic cavity (black arrow) and liver (white arrow).

biliary tract or bronchioles (1). Direct rupture is what happened in our case: spillage of the contents occurred to the abdominal or pleural cavity. Although the diameter of the cyst cavity was approximately $20 \mathrm{~cm}$, the patient did not have any complaints before the rupture and anaphylaxis. Anaphylaxis because of spontaneous rupture in the peritoneal cavity is a rare but mortal complication of hydatid disease (1-6). Surgery is still the gold standard treatment modality. Removing the antigenic material by peritoneal washing is the mainstay for solving anaphylactic events. The solution used for washing the peritoneal cavity after rupture is still debatable (47). Hypertonic solutions may cause fluid-electrolyte imbalance, or poviodine or cetrimide may result in toxicity. Isotonic crystalloid fluid solution is preferred (5). We used diluted poviodine solution for washing the whole abdominal cavity. Definitive surgery such as hepatectomy (radical, lower recurrence with a higher operative risk) or deroofing (drainage of cyst content by removing part of the cyst wall) with or without omentoplasty (conservative) can also be performed to prevent recurrences $(1,4,8)$. The overall recurrence 


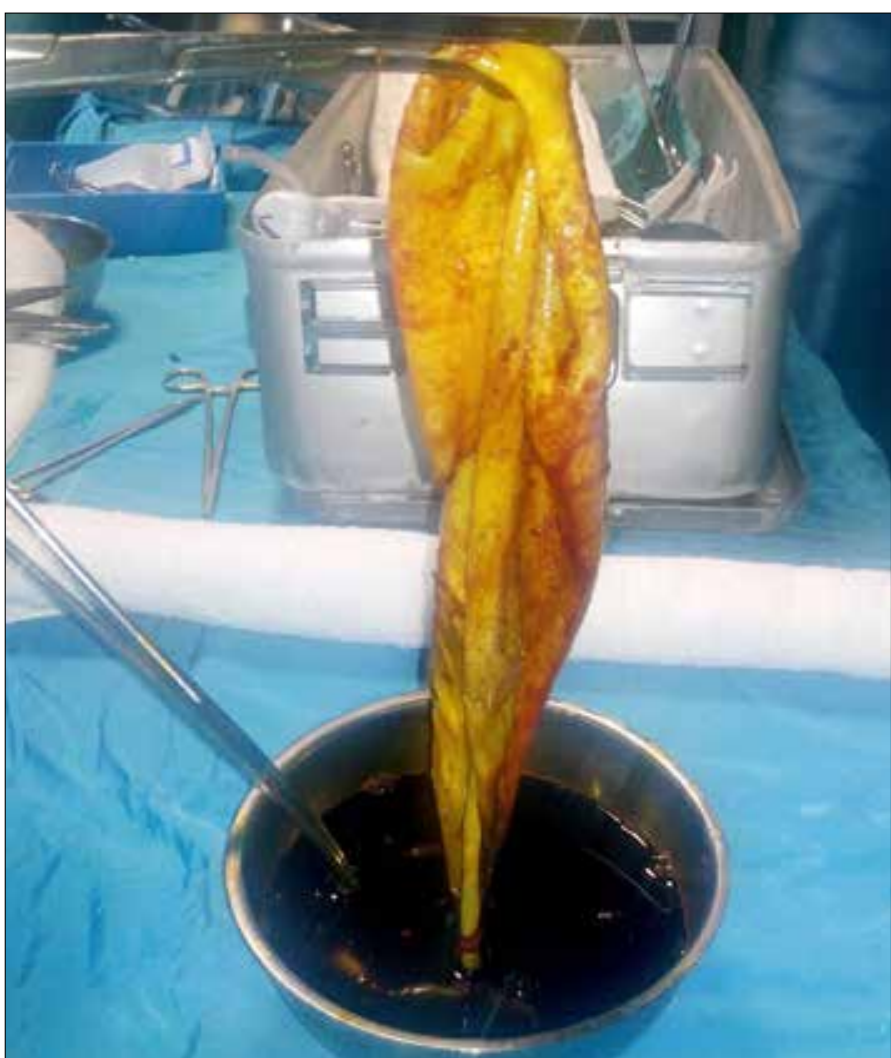

FIG. 3. Typical appearance of the germinative membrane of a hydatid cyst.

rate is $2 \%-25 \%$ and mortality rate is $0.5 \%-4 \%(1,4)$. We preferred deroofing and omentoplasty because of the condition of the patient. Anthelmintic medications should be postoperatively administered even after discharge.

\section{Conclusion}

Abdominal pain and anaphylaxis are uncommon clinical features in our daily surgical practice. Thus, hydatid disease must be kept in mind in patients with abdominal pain and anaphylactic findings, es- pecially in endemic areas, to minimize the mortality risk in this condition that can be easily managed.

Informed Consent: Written informed consent was obtained from patient who participated in this case.

Peer-review: Externally peer-reviewed.

Author Contributions: Concept - C.A.; Design - Ö.A.Ç., S.U.Ç.; Supervision Ö.A.Ç., C.A.; Materials - Ö.A.Ç., S.U.Ç., A.F.K.; Data Collection and/or Processing - S.U.Ç., A.F.K.; Literature Review - S.U.Ç., E.O.K.; Writer - Ö.A.Ç., S.U.Ç.; Critical Review - C.A., Ö.A.Ç.

Conflict of Interest: The authors declared no conflict of interest.

Financial Disclosure: The authors declared that this study has received no financial support.

\section{References}

1. Tinsley B, Abbara A, Kadaba R, Sheth H, Sandhu G. Spontaneous Intraperitoneal Rupture of a Hepatic Hydatid Cyst with Subsequent Anaphylaxis: A Case Report. Case Reports Hepatol 2013; 2013: 320418. [CrossRef]

2. Castanares-Zapatero D, Laterre PF. Ruptured hydatid cyst in a patient with shock. Hepatobiliary Pancreat Dis Int 2009; 8: 638-9.

3. Yilmaz M, Akbulut S, Kahraman A, Yilmaz S. Liver Hydatid Cyst Rupture Into the Peritoneal Cavity After Abdominal Trauma: Case Report and Literature Review. Int Surg 2012; 97: 239-44. [CrossRef]

4. Nunnari G, Pinzone MR, Gruttadauria S, Celesia BM, Madeddu G, Malaguarnera $\mathrm{G}$, et al. Hepatic echinococcosis: clinical and therapeutic aspects. World J Gastroenterol 2012; 18: 1448-58. [CrossRef]

5. Akcan A, Akyildiz H, Artis T, Ozturk A, Deneme MA, Ok E, et al. Peritoneal perforation of liver hydatid cysts: clinical presentation, predisposing factors, and surgical outcome. World J Surg 2007; 31: 1284-91. [CrossRef]

6. Sanei B, Hashemi SM, Mahmoudieh M. Anaphylactic shock caused by nonruptured hydatid cyst of the liver. J Gastrointest Surg 2008; 12 2243-5. [CrossRef]

7. De Wispelaere L, Vande Velde S, Schelstraete P, Van Renterghem K, Moerman F, Van Biervliet S, et al. Anaphylactic shock as a single presentation of Echinococcus cyst. Acta Gastroenterol Belg 2011; 74: 462-4.

8. Marriott PJ, Karani J, Lucas SB, Chiodini PL, Heaton ND. Anaphlaxis from intravascular rupture of Hydatid disease following liver trauma. J Surg Case Rep 2010; 2010: 1-5. 